\title{
Latent inhibition of conditioned disgust reactions in rats
}

\author{
Matías López, Patricia Gasalla, and Mercedes Vega \\ University of Oviedo, Oviedo, Spain \\ AND \\ Cheryl L. Limebeer, Erin M. Rock, Katharine J. Tuerke, \\ Holly Bedard, ANd Linda A. PARKer \\ University of Guelph, Guelph, Ontario, Canada
}

\begin{abstract}
The present experiments, using the latent inhibition (LI) paradigm, evaluated the effect of nonreinforced exposure to saccharin on the acquisition of an LiCl-induced saccharin aversion as measured by conditioned disgust reactions in the taste reactivity test and conditioned taste avoidance in a consumption test. When rats were preexposed to saccharin by bottle exposure (Experiments 1 and 3), LI was evidenced only by conditioned taste avoidance (bottle testing), but not by conditioned disgust reactions (intraoral [IO] testing). On the other hand, when rats were preexposed to saccharin by IO infusion (Experiments 2 and 3), LI was evidenced only by conditioned disgust reactions, but not by conditioned taste avoidance. Experiment 4 showed that LI of conditioned disgust reactions does not appear to be affected by a context shift from preexposure to testing phases. These results show that the expression of LI of both conditioned taste avoidance and conditioned disgust reactions depends critically on a common method of flavor exposure during preexposure and testing.
\end{abstract}

A conditioned taste aversion (CTA) is formed when an animal, usually a rat, associates a novel taste with subsequent visceral malaise produced by a drug with known emetic properties (see Reilly \& Schachtman, 2009, for a recent review on this behavioral phenomenon). This paradigm typically involves conditioning trials in which thirsty rats voluntarily consume the novel flavor from a bottle shortly before the emetic agent (e.g., lithium chloride, $\mathrm{LiCl}$ ) is administered. Conditioned aversion is then measured as decreased voluntary intake of flavor upon reexposure (consumption test). This procedure requires the rat to display both preparatory/appetitive responses of approaching the bottle containing the flavored solution and consummatory responses of drinking from the spout in accordance with Konorski's (1967) model of motivated behavior. Thus, it is conceivable that the preparatory responses, in addition to the consummatory responses, became associated with the illness. The taste reactivity (TR) test (Grill \& Norgren, 1978) is an alternative measure of a conditioned taste aversion. This test measures the orofacial reactions elicited by an intraoral (IO) infusion of the flavor directly in the rat's mouth. If the rat learns the flavor-illness association, it will display conditioned disgust reactions, such as gaping, when intraorally infused with the previously lithium-paired flavor. Using this methodology, neither the acquisition nor the expression of a flavor-illness association includes the appetitive phase of responding. Therefore, the contribution of changes in consummatory responding independent of preparatory responding to taste aversion learning can be evaluated with the TR test.

It is well known that nonreinforced exposure to a flavor to be associated with illness interferes with the development of the taste aversion, a phenomenon referred to as latent inhibition (LI; see Lubow, 1989, 2009). Although the LI effect with a CTA procedure has been evaluated extensively using the consumption test (i.e., preexposure retards subsequent suppressed consumption of an illnesspaired flavor), the effect of flavor preexposure on conditioned disgust has not been assessed. Given that preparatory and consummatory responses can be involved when a rat acquires a taste aversion, it is unclear whether the LI effect in taste aversion is based on a weakened tendency to approach and maintain contact with the bottle containing the flavor, on a weakened rejection reaction (conditioned disgust), or both. The broad goal of the present study is to provide a demonstration that flavor familiarity attenuates CTA based on acquired disgust. We assessed whether nonreinforced exposure to saccharin prior to conditioning with $\mathrm{LiCl}$ retards both suppressed consumption and conditioned disgust reactions.

In each of the following experiments, rats were conditioned by IO infusion in a TR test and were tested both in the TR test and in the consumption test. In different experiments, prior to conditioning with $\mathrm{LiCl}$, rats were preexposed to a saccharin solution by bottle or by IO infusion. The effect of prior flavor exposure on conditioned 
disgust reactions and conditioned taste avoidance was then assessed.

\section{EXPERIMENT 1}

The aim of this experiment was to test whether nonreinforced exposure to a flavor attenuates the acquisition of a LiCl-induced taste aversion as measured by conditioned disgust reactions in the TR test. To our knowledge, this issue has not previously been addressed. Rats were allowed to consume either a saccharin solution (familiar condition) or water (novel condition) directly from a bottle during preexposure training. In the conditioning session, all the rats were given the saccharin solution by IO infusion and were then injected with $\mathrm{LiCl}$. On testing, the rats were intraorally infused with the saccharin solution, and their orofacial reactions were examined. After the taste reactivity test, a consumption test was conducted in order to evaluate whether previous nonreinforced exposure to the flavor retarded suppressed consumption, as well as conditioned disgust reactions.

\section{Method}

Subjects. The subjects were 20 male Sprague Dawley rats (Charles River Laboratories, St Constant, Quebec), which weighed 213-229 g at the start of the experiment. Upon arrival, they were individually housed in opaque plastic cages in a colony room maintained at $21^{\circ} \mathrm{C}$ with a $12: 12$-h light:dark cycle (lights off at 08:00 h). All experimental manipulations occurred at the same time each day during the dark portion of the cycle. Throughout the experiments, the animals were on a water deprivation schedule in which the rats received fluid in the morning as described in the procedure section and received supplementary water for $30 \mathrm{~min}$ beginning at 16:00 $\mathrm{h}$ in the afternoon. All experimental manipulations occurred during the morning session. Food was always available in the home cages. All experimental procedures were in accordance with guidelines for the care and use of laboratory animals of the Canadian Council of Animal Care and were approved by the Animal Care Committee of the University of Guelph.

Cannulation surgery. Initially, each rat was implanted with an IO cannula. On the day of surgery, the rats were anesthetized with isofluorane gas and administered Anafen ( $7 \mathrm{mg} / \mathrm{kg}$, s.c.; Merial), a nonsteroidal anti-inflammatory drug with analgesic properties. A 3-cm square of fur was shaved at the back of the neck just above the scapula, and Betadine (Purdue Frederick) and alcohol were rubbed on the skin. A thin-walled 15-gauge stainless steel needle was inserted at the back of the neck, directed subcutaneously around the ear, and brought out behind the first molar inside the mouth. A length of intramedic polyethylene tubing with an inner diameter of $0.86 \mathrm{~mm}$ and an outer diameter of $1.27 \mathrm{~mm}$ was then run through the needle, after which the needle was removed. Two square elastic disks were placed over the tubing and drawn to the exposed skin at the back of the neck for the purpose of stabilizing the cannula. The tubing was held secure in the oral cavity by an o-ring, which was sealed behind the tubing prior to cannulation surgery. Following surgery, the rats were monitored for 3 days and had their cannula flushed daily with chlorhexidine. For the purposes of conditioning and testing, the cannula was connected to an infusion pump (Harvard Apparatus, South Natick, MA) for delivery of the solution by slipping the tubing of the cannula inside a second polyethylene tubing (inner diameter, $1.19 \mathrm{~mm}$; outer diameter, $1.70 \mathrm{~mm}$ ) attached to the infusion pump.

Apparatus. The TR testing was conducted in a Plexiglas conditioning chamber located in a dark room. The chamber was made of clear Plexiglas sides $(22.5 \times 26 \times 20 \mathrm{~cm})$ with a dark lid and was placed on a table with a clear Plexiglas top. Two 50-W white lights on each side of the conditioning chamber provided a light illumination. A mirror beneath the chamber on a $45^{\circ}$ angle facilitated viewing of the ventral surface of the rat during IO infusion. The rat's cannula was attached to the infusion pump through the ceiling of the chamber, using a $30-\mathrm{cm}$ infusion hole. During the infusion, the rat's orofacial responses were videotaped using a Panasonic video camera with a telephoto lens (Sony DCR-HC48). The video camera was connected to a computer to record the orofacial reactions of the rats during conditioning and testing.

Procedure. During the course of the experiment, 4 rats lost their cannula. The remaining animals were randomly assigned to the following two groups: Group PRE (preexposed; $n=7$ ) and Group NON (nonpreexposed; $n=9$ ). Two days after recovery from surgery, the animals were placed on a water deprivation schedule by removing the drinking bottles from the home cages at 16:00 h. On the next 2 days, the rats received $15 \mathrm{~min}$ of water from graduated plastic tubes in their home cages, beginning at 08:30 $\mathrm{h}$ in the morning, and an additional $30 \mathrm{~min}$ of water beginning at $16: 00 \mathrm{~h}$ in the afternoon. The delivery of 30 min of water in the afternoon continued throughout the experiment.

The next 4 days constituted the flavor preexposure phase. During these sessions, the rats in Group PRE received access to a graduated tube containing $30 \mathrm{ml}$ of a $0.1 \%(\mathrm{w} / \mathrm{v})$ saccharin solution for $15 \mathrm{~min}$ in their home cage at 08:30 h. The animals in Group NON received equivalent exposure to water during these sessions. The fluid intake was measured in these sessions.

On the next 2 days, beginning at 8:30 h, the rats were habituated to the conditioning procedure. They were placed in the conditioning chamber with their cannula attached to the infusion pump for fluid delivery. After a 5-min period, water was infused into their IO cannula for $5 \mathrm{~min}$ at the rate of $1 \mathrm{ml} / \mathrm{min}$ in order to habituate them to this fluid presentation method. Twenty-four hours after the habituation training, the conditioning trial was administered. In this session, the rats were placed in the conditioning chamber and intraorally infused with $0.1 \%$ saccharin for $5 \mathrm{~min}$ at a rate of $1 \mathrm{ml} / \mathrm{min}$ while their orofacial responses were video recorded. Immediately following the saccharin infusion, all of the rats were injected with $\mathrm{LiCl}(20 \mathrm{ml} / \mathrm{kg}$ of $0.15 \mathrm{M} \mathrm{LiCl})$ and returned to their home cages. The day following conditioning, the rats received $15 \mathrm{~min}$ of water in their home cage at 8:30 h.

On each of the following 3 days, the rats received daily TR test trials. During these sessions, beginning at 8:30 h, the rats were intraorally infused with the saccharin solution for $5 \mathrm{~min}$ at a rate of $1 \mathrm{ml} / \mathrm{min}$, and the orofacial responses were videotaped. On the following day, the rats received $15 \mathrm{~min}$ of water in the morning. The consumption test was administered on each of the following 2 days. During each of these tests, the rats were given access to $0.1 \%$ saccharin solution in a graduated tube for $15 \mathrm{~min}$ in their home cages at $8: 30 \mathrm{~h}$, and their consumption was measured.

Behavioral measures. The videotapes were scored by an observer blind to experimental groups, using the Observer (Noldus Information Technology, Sterling, VA) event-recording program. The behaviors scored included the number of occurrences (discrete events) of the disgust reactions of gaping (rapid, large-amplitude opening of the mandible with retraction of the corners of the mouth), chin rubbing (mouth or chin in direct contact with the floor or wall of the chamber and body projected forward), and paw treading (forward and backward movement of the forepaws in synchronous alternation). The numbers of each of these events were summed to provide a total disgust reaction score. The ingestion reactions of tongue protrusions (extensions of the tongue out of the mouth) and mouth movements (movement of the lower mandible without opening the mouth) were also scored. The summation of tongue protrusions and mouth movements created a total ingestion reaction score.

\section{Results and Discussion}

During the 4-day preexposure phase, Group PRE received $0.1 \%$ saccharin solution and Group NON received water during the 15 -min morning drinking session. A 2 (group) $\times 4$ (trial) repeated measures ANOVA for the 
consumption data during the preexposure phase revealed a significant effect of trial $[F(3,42)=4.22]$ and a group $\times$ trials interaction $[F(3,42)=3.98]$. Subsequent ANOVAs for each trial revealed a significant group effect in Trial 1 $[F(1,14)=18.97]$; that is, the rats drank less saccharin solution than water. The analysis also revealed that the mean amount of fluid consumed did not significantly differ between groups on Trials $2-4(F \mathrm{~s}<1)$. The mean fluid consumptions for the two groups on the last preexposure trial were the following: Group PRE, 12.05 (SEM = $\pm 1.23)$; Group NON, $10.56(S E M= \pm 0.98)$. In this and subsequent analyses, a significance level of $p<.05$ was adopted. Values are expressed as means ( $\pm S E M \mathrm{~s})$.

Analysis of the orofacial responses elicited during the 5-min IO infusion of saccharin on the conditioning trial with $\mathrm{LiCl}$ revealed that the rats in Groups PRE and NON did not display a pattern of rejection reactions during this session. Also, analysis of the ingestion reactions expressed by the rats on the conditioning trial revealed that Group PRE and Group NON did not significantly differ $(F<1)$. The mean number of ingestion reactions for the two groups on this session were the following: Group PRE, 38.28 $( \pm 2.13)$; Group NON, $42.05( \pm 1.74)$.

Figure 1 (top panel) displays the mean number of conditioned disgust reactions (summation of gaping, chin rubbing, and paw treading) during the 5-min IO infusion of saccharin solution on each of the three TR tests. It may be seen that the mean frequency of conditioned disgust reactions declined over the trials and that the rats in Groups PRE and NON showed these reactions at a comparable level. The 2 (group) $\times 3$ (trial) ANOVA conducted on these data revealed a significant effect of the trial factor $[F(2,28)=4.19]$ but no effect of group $[F(1,14)=1.71]$ and no significant interaction between these two factors $[F(2,28)=1.33]$.

The analysis of the ingestion reactions (summation of tongue protrusions and mouth movements) during the TR test revealed that Groups PRE and NON displayed suppressed ingestion reactions in the first test trial and that the frequency of these responses increased over the test trials. The ANOVA (group $\times$ trial) conducted on these data revealed a significant effect of test trial $[F(2,28)=$ 7.66] but no effect of group and no significant interaction between these two factors $(F \mathrm{~s}<1)$. The mean frequencies of ingestion reactions for the two groups on each of the test trials were the following: Group PRE, $16.28( \pm 2.48)$, $21.85( \pm 1.87)$, and $35.33( \pm 3.31)$; Group NON, 10.85 ( \pm 2.92$), 22.44( \pm 3.42)$, and $34.00( \pm 2.17)$.

Figure 1 (bottom panel) shows the mean amount of saccharin solution consumed by Groups PRE and NON on each of the subsequent consumption tests. Fluid intake by Group NON increased over the trials, whereas intake by Group PRE remained high across the sessions. A $2 \times 2$ ANOVA of consumption scores with group and trial as factors revealed significant main effects of trial $[F(1,14)=13.49]$ and group $[F(1,14)=5.09]$ and a group $\times$ trial interaction that approached statistical significance $[F(1,14)=4.29, p=.057]$. Subsequent ANOVAs for each trial revealed a significant effect of group on Trial $1[F(1,14)=11.85]$, but not on Trial $2[F(1,14)=$ 1.22], showing evidence that Group PRE drank signifi-

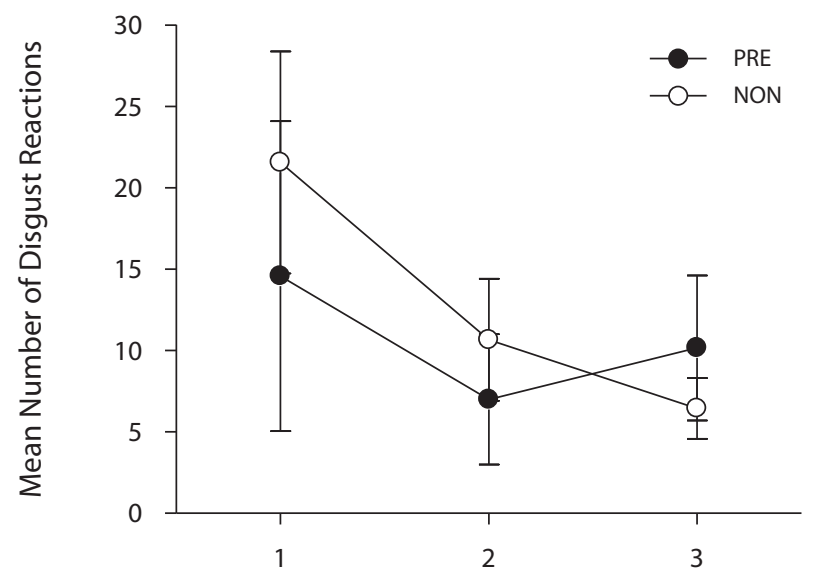

TR Test Trial

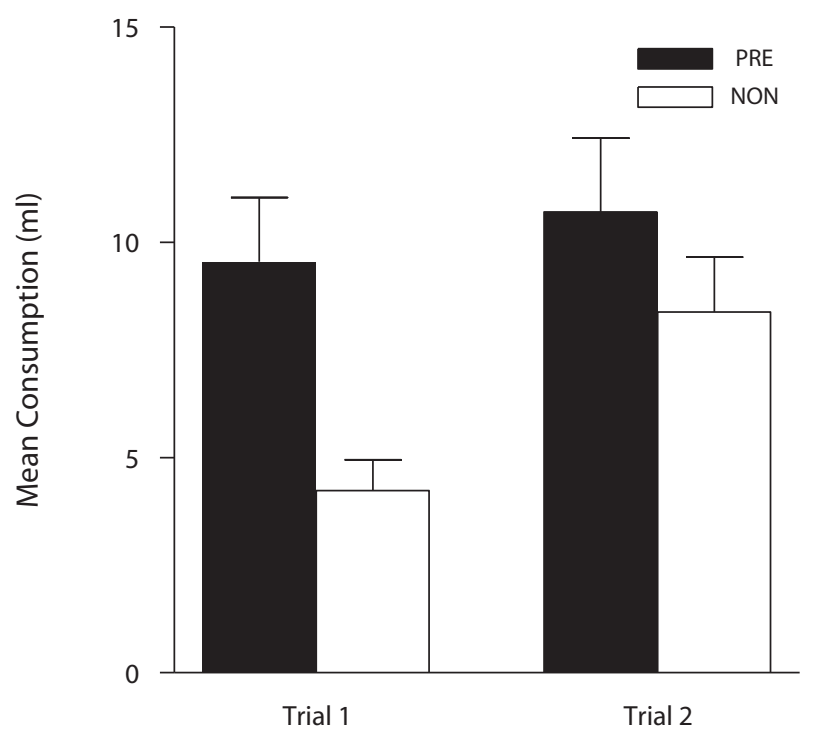

Figure 1. Mean number of conditioned disgust reactions (gaping, chin rubbing, and paw treading) elicited during the taste reactivity (TR) tests (top panel) and mean milliliters of saccharin solution consumed during the consumption test (bottom panel) in Experiment 1 when rats were preexposed to saccharin by bottle. Error bars represent the standard errors of the means. PRE, preexposed group; NON, nonpreexposed group.

cantly more of the saccharin solution than did Group NON on Trial 1, but not on Trial 2.

This experiment showed that when tested with the TR test, preexposed and nonpreexposed rats displayed conditioned disgust reactions to the previously LiCl-paired flavor. On the other hand, when tested with the bottle test, nonpreexposed rats displayed stronger suppressed consumption than did those preexposed. At first sight, these results suggest a dissociation between conditioned taste avoidance and conditioned disgust in the LI paradigm, since exposure to saccharin prior to conditioning did not affect the display of disgust reactions but did attenuate suppressed consumption. This finding is in line with the pro- 
posal by Parker (2003; Parker, Limebeer, \& Rana, 2009) that two associations may be involved in taste aversion learning, one taste-nausea association that supports conditioned disgust reactions, and the other consisting of an association between the taste and a novel change in physiological state that supports conditioned taste avoidance. It may be the case, however, that the change in the mode of flavor presentation from saccharin preexposure by bottle to saccharin exposure in testing by IO infusion may have prevented the expression of LI in the taste reactivity test. In fact, there is some evidence indicating that $\mathrm{LI}$ in taste aversion is attenuated when a shift in the flavor delivery method occurs between preexposure and conditioning (e.g., Fouquet, Oberling, \& Sandner, 2001), an effect that also includes a context change during stages of conditioning. Because, in the present experiment, all the rats had been preexposed to the saccharin solution by bottle, it is conceivable that the method of flavor presentation during preexposure and testing must be similar to reveal LI effects and that changing the presentation mode across experimental stages would attenuate the expression of LI.

\section{EXPERIMENT 2}

Because of the results in the previous experiment, we sought to explore in Experiment 2 whether flavor preexposure attenuates conditioned disgust when flavor preexposure is given by IO infusion. This experiment used the same design as the previous experiment, although in a different laboratory. The rats were preexposed to saccharin by IO infusion instead of by bottle. If the method of flavor preexposure must be consistent with the testing method to detect the expression of LI, we would predict that LI of taste aversion would be evident in the expression of conditioned disgust reactions in the TR test, but not in the expression of conditioned taste avoidance in the consumption test. Furthermore, in the present experiment, the durations of the TR test and the consumption test were equated, to address the issue that the pattern of results obtained in Experiment 1 may simply reflect differences in the durations of the two types of tests. For this purpose, the rats were intraorally infused with saccharin for 5 min during the TR test, whereas in the consumption test they received the saccharin solution in the bottle for $5 \mathrm{~min}$ in the home cages. By applying these changes in the procedure, we expected to better explore the effects of flavor familiarity on conditioned taste avoidance and conditioned disgust.

\footnotetext{
Method

Subjects and Apparatus. The subjects were 18 male Wistar rats (University of Oviedo, Spain) weighing 199-242 g at the start of the experiment. They were housed individually in polypropylene cages and were kept in a temperature-controlled room $\left(21^{\circ} \mathrm{C}\right)$ with a 12:12-h light:dark cycle (lights on between 08:00 and 20:00 h). The experiment was conducted during the light phase of the cycle. Unless otherwise stated, the procedures were identical to those employed in Experiment 1, including the same deprivation schedule with a supplementary $30 \mathrm{~min}$ of water in the afternoon. All experimental manipulations were performed in accordance with Spanish (RD-12301/2005) and European (86/609/EEC) regulations concerning animal experimentation.
}

Procedure. Throughout the experiment, 3 rats lost their cannula and were removed from the experiment. The remaining rats were randomly assigned to the following two groups: Group PRE ( $n=$ $10)$ and Group NON $(n=5)$.

Three days after recovery from surgery, water deprivation was initiated by removing the drinking bottles from the home cages at 16:00 $\mathrm{h}$. The rats were maintained on the same water deprivation schedule as that in Experiment 1. On the next 2 days, the rats were habituated to the IO method of fluid presentation. For these sessions, the rats were placed in the conditioning chamber (the TR apparatus) with their cannula attached to the infusion pump for fluid delivery. After a 5-min period, water was infused into their IO cannula for $5 \mathrm{~min}$ at the rate of $1 \mathrm{ml} / \mathrm{min}$.

On the morning session of each of the next 6 days (the preexposure phase), the subjects in Group PRE were placed in the conditioning chamber and intraorally infused with $0.1 \%$ saccharin for $5 \mathrm{~min}$ at a rate of $1 \mathrm{ml} / \mathrm{min}$, whereas those in Group NON were infused with distilled water. During these sessions, the animal's orofacial responses were video recorded. The day following the final preexposure session, the rats were given the conditioning trial. In this session, all the subjects were placed in the conditioning chamber and intraorally infused with $0.1 \%$ saccharin for $5 \mathrm{~min}$, followed by an injection of $\mathrm{LiCl}(20 \mathrm{ml} / \mathrm{kg})$. The animal's orofacial responses were video recorded during this session.

The TR test was administered after a recovery day with access to water restricted to $15 \mathrm{~min}$ in the morning session. During this session, the rats were intraorally infused with the saccharin solution for $5 \mathrm{~min}$ at a rate of $1 \mathrm{ml} / \mathrm{min}$, and the orofacial responses were videotaped. On the following day, the rats received 15 min of water in the morning session. The consumption test was administered on each of the following 3 days. During each of these sessions, the rats were given access to a graduated tube containing $30 \mathrm{ml}$ of the saccharin solution $(0.1 \% \mathrm{w} / \mathrm{v})$ for $5 \mathrm{~min}$ in their home cages in the morning session, and their consumption was measured.

\section{Results and Discussion}

No consumption data from preexposure and conditioning phases are presented because the rats were intraorally infused with the saccharin solution during these sessions. The rats did not display disgust reactions during the IO infusion with saccharin on the conditioning session, indicating the absence of any evidence of neophobia to the saccharin solution. Furthermore, the analysis of the ingestion reactions during this session revealed that the rats in Groups PRE and NON showed ingestion reactions at a similar high rate $[F(1,13)=1.32]$. The total number of ingestion reactions for the two groups in this session were the following: Group PRE, $61.12( \pm 1.80)$; Group NON, $58.15( \pm 2.14)$.

Figure 2 (top panel) shows the mean number of conditioned disgust reactions (gaping, chin rubbing, and paw treading) during the TR test by the preexposed (PRE) and nonpreexposed (NON) groups. It shows that the subjects in the familiar condition displayed fewer disgust reactions to the saccharin solution than did the subjects in the novel condition. The one-way ANOVA conducted with the data of this test revealed a significant effect of group $[F(1,13)=11.69]$. Group mean scores were $2.5( \pm 1.12)$ for the rats given preexposure and $16.4( \pm 0.74)$ for the nonpreexposed rats.

The analysis of the ingestion reactions displayed during the TR test revealed that Group PRE showed significantly more ingestion reactions than did Group NON in this session $[F(1,13)=21.09]$. The mean number of ingestion 

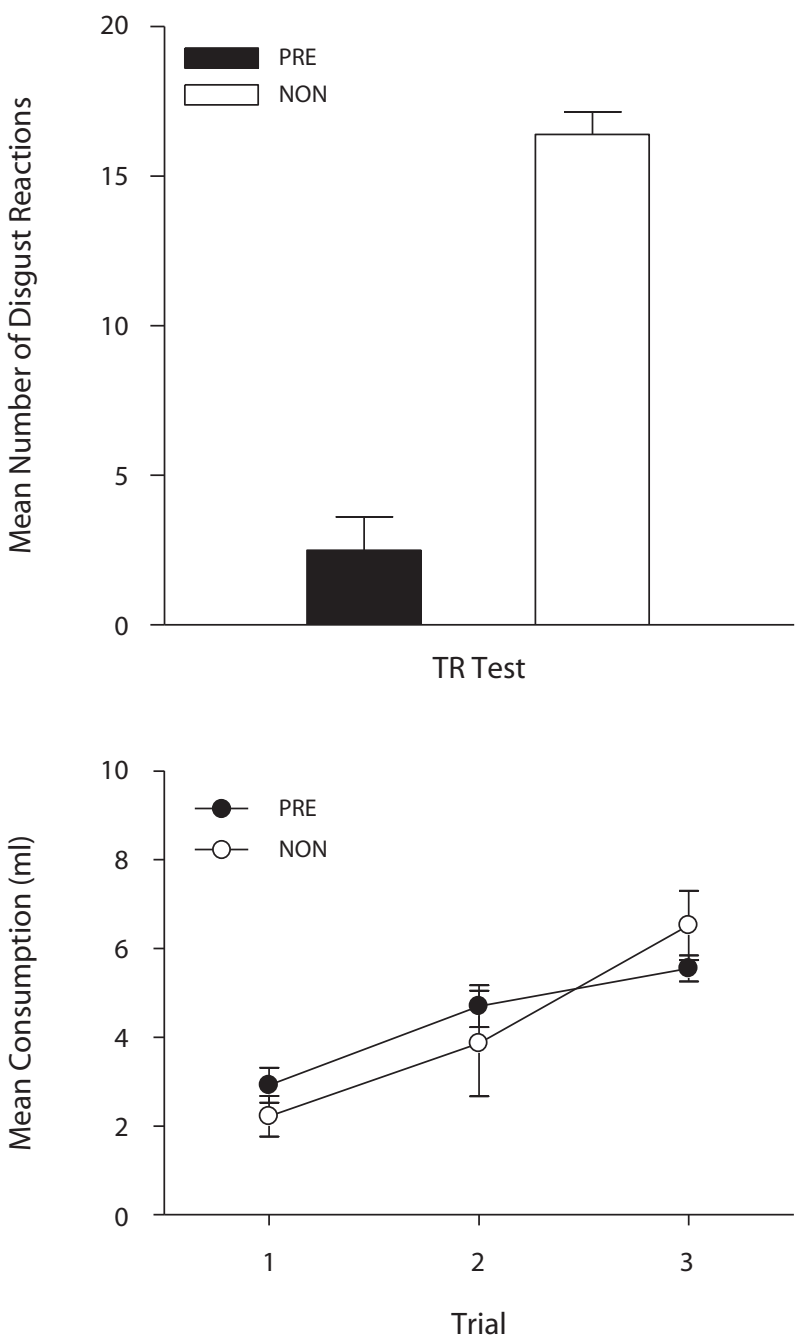

Figure 2. Mean number of conditioned disgust reactions elicited during the taste reactivity (TR) tests (top panel) and mean milliliters of saccharin solution consumed during the consumption test across trials (bottom panel) in Experiment 2 when rats were preexposed to saccharin by intraoral infusion. Error bars represent the standard errors of the means. PRE, preexposed group; NON, nonpreexposed group.

reactions emitted during this session for the two groups were the following: Group PRE, $48.16( \pm 1.45)$; Group NON, $24.15( \pm 2.13)$. Therefore, when IO infused during the preexposure, the preexposed rats displayed more ingestion reactions than did the nonpreexposed rats; however, as was observed in Experiment 1, when saccharin was delivered by bottle during preexposure, the preexposed and nonpreexposed rats did not differ in ingestion reactions. This argues for a role of fluid delivery method in determining the effects of flavor familiarity.

Group mean intake scores for the three consumption test trials (5 min each) are shown in the bottom panel of Figure 2. As is apparent, saccharin intake was suppressed in both groups on the first test trial, indicating that taste preexposure did not attenuate conditioned taste avoidance when the fluid was delivered to the animal by the IO method. The data were analyzed as a 2 (group) $\times 3$ (trial)
ANOVA, which revealed a significant main effect of test trial $[F(2,26)=23.45]$ but no effect of group $(F<1)$. The interaction between these variables was not significant $[F(2,26)=2.95]$. This analysis confirms that the results obtained in this experiment might not be attributed to differences in the duration of the consumption and TR tests.

This experiment shows that method of flavor delivery during preexposure must be consistent with the testing method to detect the expression of LI of both conditioned taste avoidance and conditioned disgust reactions. The pattern of results obtained in this experiment is just the opposite of that obtained in Experiment 1. When preexposed by bottle, LI was evidenced only by taste avoidance (bottle test), but not by disgust reactions (IO test). In contrast, in the present experiment, when preexposed by IO infusion, the rats did not show disgust reactions, but taste avoidance was evident during the consumption test. As was mentioned above, there is some evidence from the literature on taste aversion showing that changing the method of flavor presentation between preexposure and conditioning phases weakens the LI effect (e.g., Fouquet et al., 2001; Yamamoto, Fresquet, \& Sandner, 2002). The present experiment demonstrates that shifting the method of flavor presentation between preexposure and testing also interferes with the expression of LI of a taste aversion.

\section{EXPERIMENT 3}

Although the results in the previous experiments indicate that the expression of LI of both taste avoidance and conditioned disgust depends on a common method of flavor delivery (by either bottle or IO infusion) during preexposure and testing, they do not allow a direct comparison of the two delivery modes in preexposure. For this reason, the aim of Experiment 3 was to provide a direct comparison of the two fluid delivery methods during preexposure, equating the amount of fluid delivered by bottle or by IO infusions. It may be that the number and duration of the flavor preexposure sessions (four 15-min preexposure trials by bottle in Experiment 1 and six 5-min IO infusions in Experiment 2) affect the expression of LI, rather than the preexposure method per se. In the present experiment, the number and duration of the flavor preexposure sessions was held constant while the method of flavor presentation was manipulated. Two groups of rats had familiarization with the saccharin solution (three 10-min sessions) by either bottle or IO infusion, whereas another two groups received equivalent exposure to water during this phase. All the rats received the saccharin solution by IO infusion during the conditioning trial and were subsequently tested for disgust reactions in the TR test and taste avoidance in the consumption test.

\section{Method}

Subjects and Apparatus. Forty-four male Wistar rats weighing 216-313 g at the start of the experiment were used. Unless otherwise specified, Experiment 3 was conducted in a similar manner as Experiment 1. Two rats lost their cannula throughout the experiment and were removed from it. The remaining rats were randomly assigned to the following four groups: Group PRE-IO $(n=11)$, Group PRE-BTL $(n=11)$, Group NON-IO $(n=10)$, and Group NON-BTL $(n=10)$. 
Procedure. Following recovery from the surgery, the rats were placed on a water deprivation schedule as in the previous experiments. On the next day, they were habituated to the IO method of fluid ( 1 day). During this session, the rats were placed in the conditioning chamber with their cannula attached to the infusion pump for fluid delivery. After a 5-min period, water was infused into their IO cannula for $10 \mathrm{~min}$ at the rate of $1 \mathrm{ml} / \mathrm{min}$ in the morning session. The next 3 days constituted the preexposure phase. On each of these days during the morning session, the rats in Group PRE-IO were intraorally infused with $0.1 \%$ saccharin for $10 \mathrm{~min}$ at a rate of $1 \mathrm{ml} / \mathrm{min}$, whereas those in Group NON-IO were infused with distilled water for $10 \mathrm{~min}$ at the same rate. During these sessions, the bottle groups received 10-min access to a bottle containing $10 \mathrm{ml}$ of saccharin (Group PRE-BTL) or water (NON-BTL) in the home cages. In this way, all groups were equated in terms of amount of exposure to the fluid and the duration of the preexposure session.

One day after the last preexposure session, the rats were given the conditioning trial. In the morning session, all the rats received a 10-min IO infusion of $10 \mathrm{ml}$ of the saccharin solution, followed immediately by an injection of $0.15 \mathrm{M} \mathrm{LiCl}(20 \mathrm{ml} / \mathrm{kg}$ i.p. $)$. The animal's orofacial responses were video recorded during this session. The TR test was administered after a recovery day with access to water restricted to $10 \mathrm{~min}$ in the morning session. During the TR test, the rats were intraorally infused with the saccharin solution for $10 \mathrm{~min}$ at a rate of $1 \mathrm{ml} / \mathrm{min}$, and the orofacial responses were videotaped. Finally, a consumption test was administered on each of the following 3 days. During each of these sessions, the rats were given access to a graduated tube containing $30 \mathrm{ml}$ of the saccharin solution $(0.1 \% \mathrm{w} / \mathrm{v})$ for $10 \mathrm{~min}$ in their home cages in the morning session, with the amount consumed measured.

\section{Results and Discussion}

The rats in Groups PRE-BTL and NON-BTL drank all of the solutions (saccharin and water, respectively) available to them during the preexposure phase. No consumption data from the conditioning phase are presented, because all the rats were given the saccharin solution by IO infusion during this session. As in the previous experiments, there was no evidence that saccharin produced a neophobic response, since the rats did not show disgust reactions during the conditioning session. Also, the analysis of ingestion reactions during this session showed that the groups did not significantly differ in the frequency of ingestion reactions. The ANOVA conducted with these data showed no significant main effect of preexposure or method of presentation and no significant interaction between these factors $(F \mathrm{~s}<1.28)$. The mean frequency of ingestion reactions for the different groups was the following: Group PRE-BTL, 52.84 ( \pm 3.15 ); Group PRE-IO, 55.23 ( \pm 2.32 ); Group NON-BTL, 49.64 ( \pm 2.85$)$; and Group NON-IO, $51.34( \pm 3.47)$.

The results for the TR and consumption tests are shown in Figure 3. The top panel of this figure shows the mean number of disgust reactions elicited by the IO infusion of saccharin during the TR test. It shows that the rats intraorally infused with saccharin during the preexposure phase, Group PRE-IO, displayed fewer conditioned disgust reactions than did the other three groups during this test. An ANOVA was conducted on the data in this test, with fluid delivery method (IO infusion or bottle) and preexposure treatment (saccharin or water) as betweensubjects factors. There was a significant main effect of presentation method $[F(1,38)=19.79]$, but not of pre- exposure condition $[F(1,38)=3.50]$. In addition, there was a significant interaction $[F(1,38)=7.02]$ between delivery method and preexposure condition, reflecting the fact that the attenuation effect of taste familiarity on the establishment of conditioned disgust reactions depends on the mode of presentation of the flavor during preexposure. An analysis of the interaction between method and preexposure factors showed that preexposed and nonpreexposed rats differed in the IO condition $[F(1,38)=14.15]$, thus replicating the effect described in Experiment 2 that flavor preexposure by IO infusion attenuates the establish-

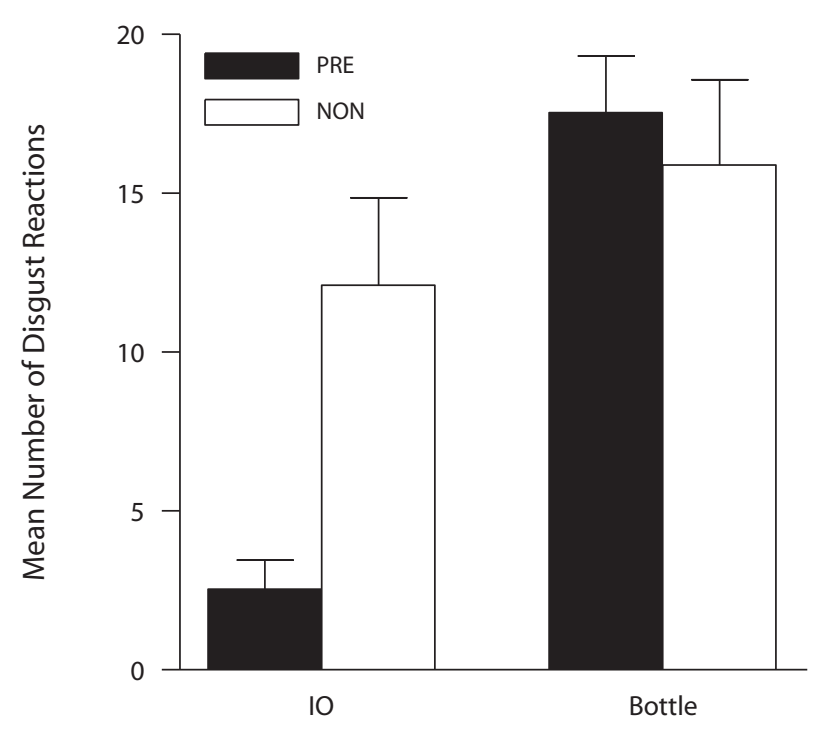

TR Test

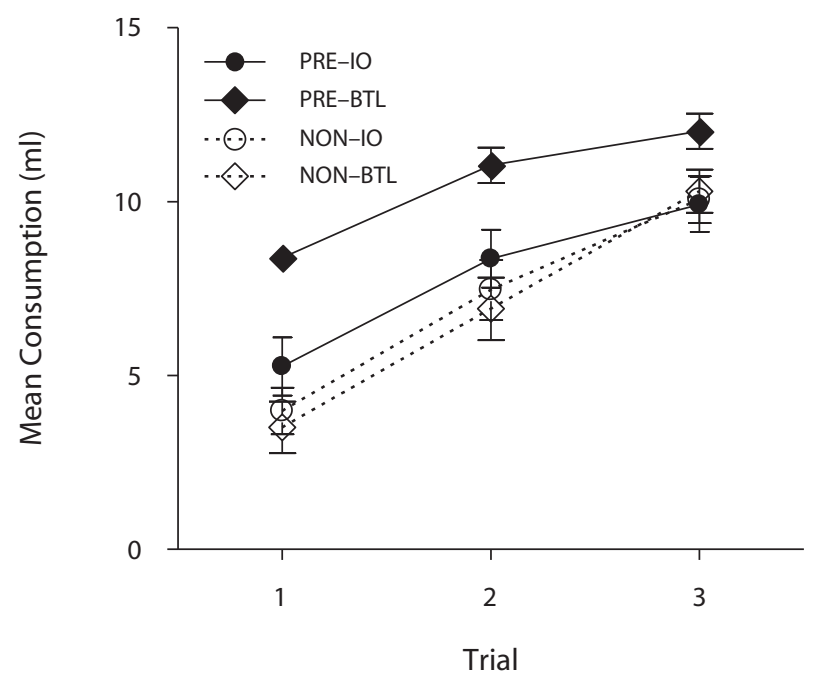

Figure 3. Mean number of conditioned disgust reactions elicited during the taste reactivity (TR) test (top panel) and mean milliliters of saccharin solution consumed during the consumption test across trials (bottom panel) in Experiment 3 when rats were preexposed to saccharin by either intraoral (IO) infusion or by bottle (BTL). Error bars represent the standard errors of the means. PRE, preexposed; NON, nonpreexposed. 
ment of conditioned disgust reactions. There was no difference between the preexposed and nonpreexposed rats in the bottle condition $(F<1)$, thus confirming the finding in Experiment 1 that flavor preexposure by bottle did not affect the expression of disgust reactions.

Group mean scores (consumption of the saccharin solution) for the three consumption test trials are presented in the bottom panel of Figure 3. This figure shows that the subjects in Group PRE-BTL consumed more of the saccharin solution than did the other three groups across the 3 days of the consumption test. The consumption data were analyzed by a $2 \times 2 \times 3$ mixed-factors ANOVA with the between-groups factors of presentation method (bottle or IO infusion) and preexposure condition (saccharin or water) and the within-group factor of test trial (1-3). The analysis revealed significant between-groups effects of presentation method $[F(1,38)=6.26]$ and preexposure condition $[F(1,38)=13.51]$ and a presentation method $\times$ preexposure condition interaction $[F(1,38)=5.24]$. Furthermore, the analysis revealed a significant within-group effect of trial $[F(2,76)=119.43]$ and a significant interaction of preexposure condition and trial $[F(2,76)=5.97]$. Subsequent comparisons among the groups, using the StudentNewman-Keuls test $(p<.05)$, revealed that Group PREBTL displayed significantly more intake of saccharin than did the other three groups on Test Trials 1 and 2, but not on Trial 3.

The findings from this experiment confirm those reported in the previous experiments when the two fluid delivery methods in preexposure are directly compared and the number and duration of the flavor preexposure trials are held constant. Likewise, the durations of the TR test and the bottle test were equated in this experiment. As in Experiment 1, when preexposed by bottle, the rats displayed conditioned disgust reactions to saccharin, but they drank the solution in the consumption test; in contrast, as in Experiment 2, when intraorally infused during preexposure, the rats did not express conditioned disgust reactions but showed a reduction in flavor consumption. Thus, this pattern of results indicates that familiarization with the flavor prior to conditioning has a different effect on taste avoidance and conditioned disgust reactions depending on the method of taste delivery during preexposure. More specifically, our data suggest that the expression of LI of both conditioned taste avoidance and conditioned disgust reactions depends critically on a common method of flavor presentation during preexposure and testing phases.

\section{EXPERIMENT 4}

Because, in the previous experiments, the TR test was given in the TR chamber, whereas the consumption test was given in the home cages, this context change could contribute to the observed effect - that is, the differential influence of flavor preexposure method on the display of attenuated taste avoidance or conditioned disgust. Indeed, some studies have reported that LI of flavor avoidance can be attenuated by contextual manipulations (e.g., Hall \& Channell, 1986). To address this issue, in the present experiment, the rats were given IO preexposure to saccharin either in the TR chamber (Group P-SAME) or in the home cages (Group P-DIFF), following which both groups were conditioned in the IO mode in the conditioning chamber. A third group of rats (Group NON) was not preexposed to the saccharin solution. Thus, if flavor preexposure by IO infusion produces LI of conditioned disgust reactions independently of the preexposure context, the method of fluid presentation during preexposure and testing is the critical variable in producing an LI effect.

\section{Method}

The subjects were 20 male Wistar rats (University of Oviedo, Spain) weighing 258-333 g at the start of the experiment. They were implanted with an IO cannula as described in Experiment 1. Two rats lost their cannula and were removed from the experiment. The remaining rats were randomly assigned to the following three groups of subjects: Group P-SAME $(n=6)$, Group P-DIFF $(n=7)$, and Group NON $(n=5)$.

All procedural details were identical to those in Experiment 2, except as indicated. Following introduction of the water deprivation schedule, all the rats received two sessions of habituation to the IO method of fluid presentation. The first day, the rats were intraorally infused with distilled water for $2.5 \mathrm{~min}$ at a rate of $1 \mathrm{ml} / \mathrm{min}$ in the conditioning chamber. On the second habituation day, they were intraorally infused with water for $2.5 \mathrm{~min}$ in the home cages.

On the morning session of each of the next 4 days (preexposure phase), the rats in Group P-SAME were placed in the conditioning chamber and were intraorally infused with $0.1 \%$ saccharin for $5 \mathrm{~min}$ at a rate of $1 \mathrm{ml} / \mathrm{min}$, whereas those in Group P-DIFF were infused with saccharin for $5 \mathrm{~min}$ in their home cages. On these days, the rats in Group NON received two daily IO infusions with water for $2.5 \mathrm{~min}$, first in the conditioning chamber and then in the home cages. During these sessions, the rats' orofacial responses were video recorded. The day following the final preexposure session, the rats received the conditioning trial. In this session, all the subjects were placed in the conditioning chamber and intraorally infused with $0.1 \%$ saccharin for $5 \mathrm{~min}$, followed by an injection of $\mathrm{LiCl}(20 \mathrm{ml} / \mathrm{kg})$. The animal's orofacial responses were video recorded during this session.

In the TR test, the rats were intraorally infused with the saccharin solution for $5 \mathrm{~min}$ at a rate of $1 \mathrm{ml} / \mathrm{min}$, and the orofacial responses were videotaped. After an additional session with water in the home cages, the consumption test was administered for 3 days. During each of these sessions, the rats were given access to a graduated tube containing $30 \mathrm{ml}$ of the saccharin solution for $5 \mathrm{~min}$ in their home cages at 10:00 h, and their consumption was measured.

\section{Results and Discussion}

As in the previous experiments, the rats did not show disgust reactions during the $\mathrm{IO}$ infusion of saccharin on the conditioning day, indicating the absence of a neophobic response to the saccharin solution. As well, there were no differences between groups in the number of ingestion reactions (tongue protrusions and mouth movements) during this session $[F(2,15)=1.04]$. The total number of ingestion reactions for the three groups in this session was the following: Group P-SAME, 48.30 ( \pm 1.18$)$; Group PDIFF, $51.76( \pm 2.04)$; and Group NON, $47.24( \pm 0.89)$.

The mean number of conditioned disgust reactions expressed by the rats during the TR test is presented in Figure 4 (top panel). It shows that the rats preexposed to the saccharin solution (Groups P-SAME and P-DIFF) displayed fewer disgust reactions than did the subjects in the nonpreexposed group (Group NON). A one-way ANOVA conducted with these scores revealed a significant effect 
of group $[F(2,15)=4.12]$. Post hoc Student-NewmanKeuls comparisons $(p<.05)$ showed no differences between Groups P-SAME and P-DIFF, but these two groups significantly differed from Group NON. The mean number of disgust reactions during this session for each group was the following: Group P-SAME, 3.33 ( \pm 0.98$)$; Group P-DIFF, $4.0( \pm 1.69)$; and Group NON, $12.2( \pm 2.05)$. This result resembles that in Experiments 2 and 3 and indicates that preexposure context is not important for determining the effect of flavor preexposure on the attenuation of conditioned disgust reactions. Likewise, the preexposure context did not determine the effect of flavor exposure on the frequency of ingestion reactions in the TR test. As in Experiments 2 and 3, the preexposed rats displayed more ingestion reactions than did the nonpreexposed rats. The one-way ANOVA conducted with these scores showed a significant effect of group $[F(2,15)=12.29]$. Post hoc Student-Newman-Keuls comparisons $(p<.05)$ showed no differences between Groups P-SAME and P-DIFF, but these two groups significantly differed from Group NON. The mean frequency of ingestion reactions displayed during this session for the different groups was the following: Group P-SAME, $36.12( \pm 2.13)$; Group P-DIFF, 41.23 $( \pm 1.88)$; and Group NON, $21.52( \pm 0.97)$.

The bottom panel of Figure 4 shows the group mean amount consumed by the different groups during the consumption test (3 days). As before, saccharin consumption was suppressed in the first test trial, and the groups did not differ across the three test trials. An ANOVA with group and trial as the variables revealed a significant main effect of test trial $[F(2,30)=106.56]$, but no effect of group $(F<1)$. The interaction between these variables was not significant $[F(4,30)=1.74]$.

In this experiment, therefore, the effect seen in Experiments 2 and 3, that flavor preexposure attenuated conditioned disgust reactions, was replicated using a procedure in which the flavor was given by IO infusion during preexposure and testing. In addition, this experiment showed that absence of an effect of flavor preexposure on conditioned taste avoidance reflects the shift in flavor exposure method from preexposure to testing phases, and not a simple context change effect.

\section{GENERAL DISCUSSION}

Although preexposure to a flavor prior to flavor-illness pairings clearly retards the establishment of a CTA when assessed by the typical consumption test (e.g., Revusky \& Bedarf, 1967; Siegel, 1974), the effect of flavor preexposure on the establishment of conditioned disgust reactions in the TR test had not been previously tested. The present study demonstrated for the first time that prior preexposure to the to-be-conditioned flavor not only disrupts suppressed consumption, but also attenuates the development of conditioned disgust reactions. On the other hand, these experiments reveal differences in the expression of LI of both suppressed consumption and disgust reactions, depending on a similarity in the mode of flavor delivery during preexposure and testing phases. Specifically, when the rats were given saccharin by bottle during the preexposure
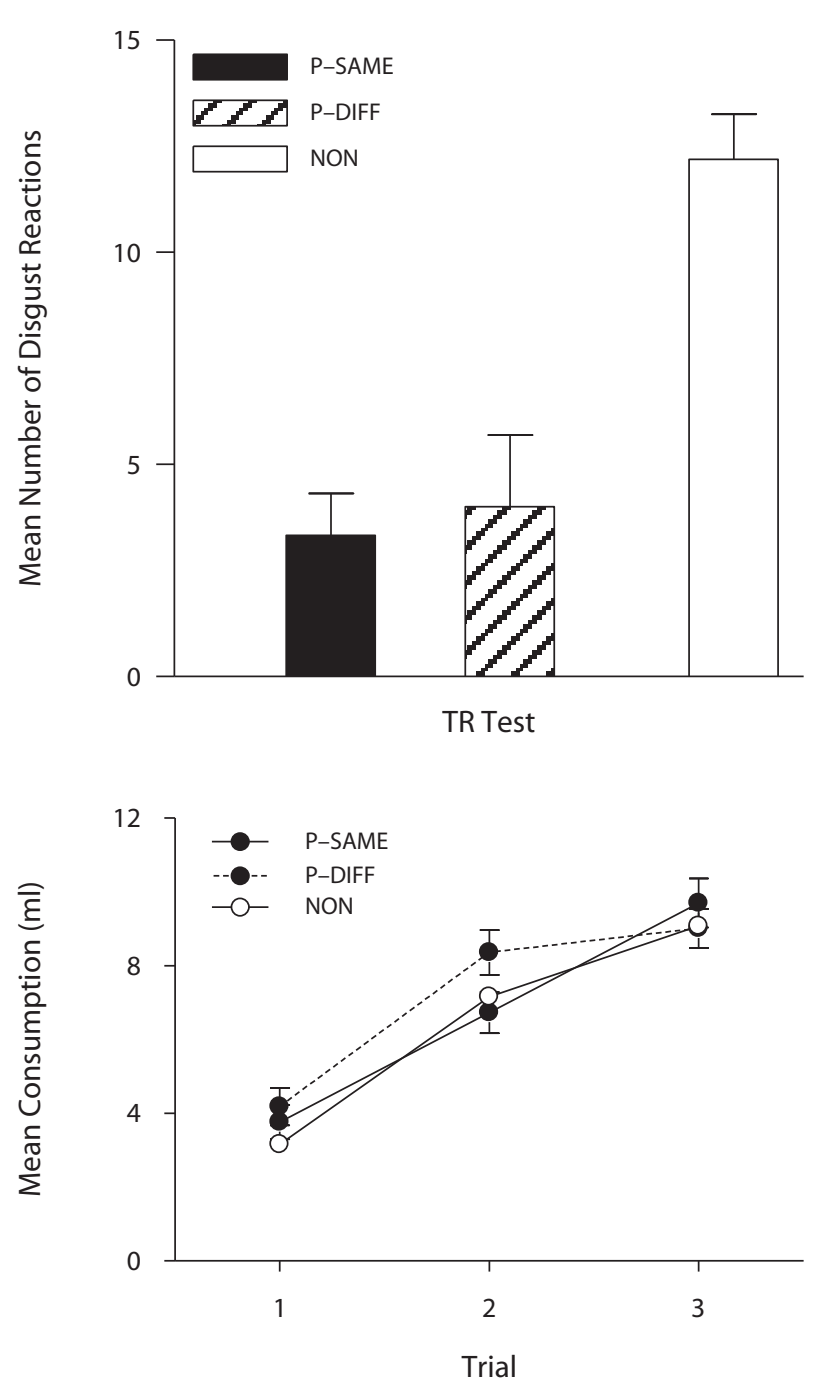

Figure 4. Mean number of conditioned disgust reactions elicited during the taste reactivity (TR) test (top panel) and mean milliliters of saccharin solution consumed during the consumption test across trials (bottom panel) in Experiment 4. During preexposure $(P)$, the rats were intraorally infused with saccharin either in the conditioning chamber (Group P-SAME) or in the home cages (Group P-DIFF) or were nonpreexposed (Group NON). Error bars represent the standard errors of the means.

phase (Experiment 1), nonreinforced exposure to saccharin prior to conditioning resulted in attenuated conditioned taste avoidance, as assessed by the amount consumed from a bottle containing the solution. In contrast, the preexposure training did not attenuate the conditioned disgust reactions elicited by the saccharin solution when intraorally infused into the rat's oral cavity. In Experiment 2, when the saccharin was delivered by the IO method during the preexposure phase, the pattern of results was opposite to that in Experiment 1; that is, flavor preexposure attenuated subsequent $\mathrm{LiCl}$-induced conditioned disgust reactions, but not suppressed consumption. In Experiment 3, the above-described pattern of results was replicated by directly comparing the two delivery methods during preexposure training. Again, the methods of flavor presenta- 
tion differentially affected the consumption of the flavor and the display of conditioned disgust reactions. When the saccharin solution was provided by bottle during the preexposure phase, the rats displayed conditioned disgust reactions, but they drank the solution in the consumption test; by contrast, when it was delivered intraorally, the rats did not display conditioned disgust reactions but showed a reduction in flavor consumption.

The results of this study suggest a role of proximal contextual stimuli in the expression of LI in the taste aversion paradigm. It may be argued that the mode of flavor presentation is indeed a proximal contextual cue (local context) that functions in the same way as more general distal cues (stimuli that are continuously present), such as those provided by the conditioning or testing apparatus. There is some suggestion that the modality of flavor delivery can effectively mediate the presence or absence of LI observed at testing. For example, Archer, Mohammed, and Järbe (1986) preexposed rats to saccharin using either quiet or noisy bottles, after which an aversion to saccharin was conditioned using the noisy bottles. An attenuation of LI was observed following a shift from the quiet to noisy conditions. More recent studies (e.g., Fouquet et al., 2001; Yamamoto et al., 2002) have also shown that changing the method of flavor presentation between preexposure and conditioning phases weakens the LI effect. In these experiments, when the rats were preexposed to the target flavor by bottle and conditioned by bottle, they displayed more LI in a bottle test than when they were preexposed by IO infusion. However, the relevance of these findings to LI of taste avoidance and conditioned disgust is unclear, since there were no control groups for flavor preexposure in these experiments.

Other studies have demonstrated that changing the general context between preexposure and testing attenuates the LI effect (e.g., Hall \& Channell, 1986). In the study by Hall and Channell, rats were conditioned and tested either in the same context as flavor preexposure or in an alternative context. Results showed that when context is changed from preexposure to testing, disruption of LI is evident. However, our finding in Experiment 4 argues against such context specificity of LI. Our results indicate that it is the method of flavor presentation, rather than the nature of the preexposure context, that is the source of the attenuation of LI. Whether rats were preexposed by IO infusion in the TR chamber or in their home cage, they displayed equally strong LI effects when assessed by disgust reactions, but no LI effect when assessed by the consumption test. Indeed, Experiment 4 replicated the effect seen in Experiments 2 and 3, indicating that when flavor preexposure is given by IO infusion, the IO test reflects attenuated conditioned disgust reactions, regardless of the context in which the flavor preexposure occurs. Furthermore, even if the saccharin IO preexposure occurs in the home cage, rats show no LI effect when tested by bottle in the home cage. Although these results cannot be explained in terms of the context specificity of LI, it might be argued that the contextual cues provided by the mode of flavor presentation are more salient (especially IO infusion) than the physical context in which preexposure or testing is carried out. It has been suggested (see Lubow, 1989) that local con- text is relatively more important than general context for classical conditioning procedures such as taste aversion learning. In addition, it should be noted that in the study by Hall and Channell, the rats were familiarized with the two contexts (discrimination training) prior to training and that such a procedure could be the necessary condition for showing control of LI by general contextual cues.

Our results are consistent with a growing body of literature indicating that the method of fluid delivery during conditioning and/or testing influences the expression of a CTA. A number of studies suggest that conditioning by IO taste exposure may produce weaker conditioning than does active consumption of the taste from a bottle (e.g., Domjan \& Wilson, 1972; Fouquet et al., 2001; Wolgin \& Wade, 1990; Yamamoto et al., 2002). More recently, however, Limebeer and Parker (2006) demonstrated that the strength of the expressed taste aversion was a function of the similarity of methods of CS exposure (bottle or IO) in conditioning and in testing, rather than simply the mode of fluid delivery per se. It has also been reported that the conditioning method influences the extinction of a CTA (e.g., Fouquet et al., 2001; Yamamoto et al., 2002). In these studies, rats conditioned by drinking actively from a bottle displayed more resistance to extinction than did rats conditioned by IO infusion, reflecting differential extinction depending on the fluid delivery method during conditioning. As well, recent work in our laboratory has shown that extinction of a taste aversion differed whether the flavor was consumed from a bottle or delivered by IO infusion during extinction phase. Taste aversion appeared to extinguish more quickly when the flavor was intraorally delivered during extinction than when actively consumed from a bottle (Cantora, López, Aguado, Rana, \& Parker, 2006).

There is controversy regarding whether LI is the result of an acquisition deficit (e.g., Mackintosh, 1975) or a retrieval interference deficit (e.g., Aguado, Symonds, \& Hall, 1994; Bouton, 1991; Kraemer \& Roberts, 1984). The interference account suggests that preexposure and conditioning experiences generate independent memories that interfere with retrieval at the time of testing. The interference interpretation of the results reported here would predict that there should be more interference at test when the method of preexposure and conditioning are different than when they are the same. In the present experiment, the rats were conditioned by IO exposure in all the experiments. However, the display of LI was critically determined by a congruity of the method of flavor exposure during preexposure and test, with the conditioning method held constant. That is, the rats preexposed by bottle displayed LI only when tested by bottle, even though they were conditioned by IO infusion. On the other hand, the rats preexposed by IO infusion and conditioned by IO infusion but tested by bottle did not display LI. This pattern of findings suggests that not only are the memories of preexposure and conditioning experiences critical for the display of LI, but also their congruity with testing procedures determines the likelihood of the display of LI.

There is additional evidence from studies examining the neural substrates underlying taste aversion learning that lesions of specific brain regions, including the amygdala 
and the gustatory cortex, eliminate CTAs, depending on the conditioning method (e.g., Fresquet, Angst, \& Sandner, 2004; Schafe, Thiele, \& Bernstein, 1998). Furthermore, recent studies using c-Fos expression as a marker of neuronal activation have reported increases in neuronal activity in brain regions involved in taste aversion learning, depending on flavor delivery method during conditioning. For example, Spray, Halsell, and Bernstein (2000) compared the IO and the bottle delivery methods, observing significant elevations in c-Fos expression in the intermediate nucleus of the solitary tract in rats that had been conditioned with the IO method, but not in animals conditioned by bottle. Recently, it has also been shown, using c-Fos immunocytochemistry, that different brain regions are activated following a novel or a familiar saccharin solution paired with $\mathrm{LiCl}$, depending on the conditioning method (by bottle or IO infusion). Exposure to a novel, but not a familiar, flavor has been found to produce increases in neuronal activation in several brain areas involved in taste aversion learning (the basolateral and central nuclei of amygdala, the insular gustatory cortex, and the nucleus of the solitary tract) when the flavor is delivered by bottle during conditioning; however, with IO infusion, increase in neuronal activation is restricted to the central nucleus of the amygdala (e.g., Koh, Wilkins, \& Bernstein, 2003; Wilkins \& Bernstein, 2006).

In conclusion, the present study indicates that nonreinforced exposure to a flavor prior to conditioning with $\mathrm{LiCl}$ attenuates both suppressed consumption and conditioned disgust reactions. However, the method of flavor presentation during preexposure and testing determines the expression of these two distinct aspects of the conditioned response in taste aversion learning. We suggest that the mode of flavor presentation is a part of the contextual cues that can modulate LI of a CTA.

\section{AUTHOR NOTE}

This research was supported by funding from the Ministry of Education and Science of Spain (MEC, PR2007-0357) to M.L. and from the Natural Science and Engineering Research Council of Canada to L.A.P. Correspondence should be addressed to M. López, Departamento de Psicología, Universidad de Oviedo, Plaza de Feijóo s/n, 33003 Oviedo, Spain (e-mail: mlopez@uniovi.es).

\section{REHERENCES}

Aguado, L., Symonds, M., \& Hall, G. (1994). Interval between preexposure and test determines the magnitude of latent inhibition: Implications for an interference account. Animal Learning \& Behavior, 22, 188-194.

Archer, T., Mohammed, A. K., \& Järbe, T. U. (1986). Contextdependent latent inhibition in taste aversion learning. Scandinavian Journal of Psychology, 27, 277-284. doi:10.1111/j.1467-9450.1986 .tb01205.x

Bouton, M. E. (1991). Context and retrieval in extinction and in other examples of interference in simple associative learning. In L. Dachowski \& C. F. Flaherty (Eds.), Current topics in animal learning: Brain, emotion, and cognition (pp. 25-53). Hillsdale, NJ: Erlbaum.

Cantora, R., López, M., Aguado, L., Rana, S., \& Parker, L. A. (2006). Extinction of a saccharin-lithium association: Assessment by consumption and taste reactivity. Learning \& Behavior, 34, 37-43.

Domuan, M., \& WiLson, N. E. (1972). Contribution of ingestive behaviors to taste-aversion learning in the rat. Journal of Comparative \& Physiological Psychology, 80, 403-412. doi:10.1037/h0032972
Fouquet, N., Oberling, P., \& SAndner, G. (2001). Differential effect of free intake versus oral perfusion of sucrose in conditioned taste aversion in rats. Physiology \& Behavior, 74, 465-474. doi:10.1016/ S0031-9384(01)00585-6

Fresquet, N., ANGSt, M.-J., \& SANDNer, G. (2004). Insular cortex lesions alter conditioned taste avoidance in rats differentially when using two methods of sucrose delivery. Behavioural Brain Research, 153, 357-365. doi:10.1016/j.bbr.2003.12.011

GriLL, H. J., \& Norgren, R. (1978). The taste reactivity test: I. Mimetic responses to gustatory stimuli in neurologically normal rats. Brain Research, 143, 263-279. doi:10.1016/0006-8993(78)90568-1

Hall, G., \& Channell, S. (1986). Context specificity of latent inhibition in taste aversion learning. Quarterly Journal of Experimental Psychology, 38B, 121-139. doi:10.1080/14640748608402224

Koh, M. T., Wilkins, E. E., \& Bernstein, I. L. (2003). Novel taste elevates $c$-fos expression in the central amygdala and insular cortex Implications for taste aversion learning. Behavioral Neuroscience, 117, 1416-1422. doi:10.1037/0735-7044.117.6.1416

KonORSKI, J. (1967). Integrative activity of the brain. Chicago: University of Chicago Press.

Kraemer, P. J., \& RoberTs, W. A. (1984). The influence of flavor preexposure and test interval on conditioned taste aversions in the rat. Learning \& Motivation, 15, 259-278. doi:10.1016/0023-9690(84)90022-5

Limebeer, C. L., \& PARKER, L. A. (2006). Effect of conditioning method and testing method on strength of lithium-induced taste aversion learning. Behavioral Neuroscience, 120, 963-969. doi:10.1037/0735 $-7044.120 .4 .963$

LuBow, R. E. (1989). Latent inhibition and conditioned attention theory. New York: Cambridge University Press.

Lubow, R. E. (2009). Conditioned taste aversion and latent inhibition: A review. In S. Reilly \& T. R. Schachtman (Eds.), Conditioned taste aversion: Behavioral and neural processes (pp. 37-57). New York: Oxford University Press.

Mackintosh, N. J. (1975). A theory of attention: Variations in the associability of stimuli with reinforcement. Psychological Review, 82, 276-298. doi: $10.1037 / \mathrm{h} 0076778$

PARKER, L. A. (2003). Taste avoidance and taste aversion: Evidence for two different processes. Learning \& Behavior, 31, 165-172.

Parker, L. A., Limebeer, C. L., \& Rana, S. A. (2009). Conditioned disgust, but not conditioned taste avoidance, may reflect conditioned nausea in rats. In S. Reilly \& T. R. Schachtman (Eds.), Conditioned taste aversion: Behavioral and neural processes (pp. 92-113). New York: Oxford University Press.

Reilly, S., \& Schachtman, T. R. (Eds.) (2009). Conditioned taste aversion: Behavioral and neural processes. New York: Oxford University Press.

RevUSKY, S. H., \& BEDARF, E. W. (1967). Association of illness with prior ingestion of novel foods. Science, 155, 219-220.

Schafe, G. E., Thiele, T. E., \& Bernstein, I. L. (1998). Conditioning method dramatically alters the role of amygdala in taste aversion learning. Learning \& Memory, 5, 481-492. doi:10.1101/lm.5.6.481

SiEgEL, S. (1974). Flavor preexposure and "learned safety." Journal of Comparative \& Physiological Psychology, 87, 1073-1082. doi: $10.1037 / \mathrm{h} 0037599$

Spray, K. J., Halsell, C. B., \& Bernstein, I. L. (2000). c-Fos induction in response to saccharin after taste aversion learning depends on conditioning method. Brain Research, 852, 225-227. doi:10.1016 S0006-8993(99)02203-9

Wilkins, E. E., \& Bernstein, I. L. (2006). Conditioning method determines patterns of $c$-fos expression following novel taste-illness pairing. Behavioural Brain Research, 169, 93-97. doi:10.1016/j .bbr.2005.12.006

Wolgin, D. L., \& WADE, J. V. (1990). Effect of lithium chloride-induced aversion on appetitive and consummatory behavior. Behavioral Neuroscience, 104, 438-440. doi:10.1037/0735-7044.1043.438

Yamamoto, J., Fresquet, N., \& Sandner, G. (2002). Conditioned taste aversion using four different means to deliver sucrose to rats. Physiology \& Behavior, 75, 387-396. doi:10.1016/S0031-9384(01)00671-0

(Manuscript received July 7, 2009; revision accepted for publication December 4, 2009.) 